\title{
Utilización de catéteres uretrales en procedimientos de anastomosis intestinal
}

\author{
Ricardo Corrales Viera ${ }^{1} \bowtie$, Tania Guerra Álvarez ${ }^{1}$, Rebeca Solera García ${ }^{1}$, Marcela Vega ${ }^{2}$ \\ 1 Centro VIP, Concepción de Tres Ríos, Costa Rica. Email: racviera@yahoo.com, tania.guerra@yahoo.com, \\ centrovipcr@gmail.com \\ 2 IMAVET, Cartago, Costa Rica. Email: imavetmvo@gmail.com
}

La anastomosis intestinal es un procedimiento quirúrgico que se realiza en casos de obstrucción intestinal ocasionado por cuerpos extraños, disfunción de un segmento, intususcepción, neoplasias, abscesos, debilitación, vólvulo o torsión, trauma, hernia, desórdenes neurológicos, constipación crónica (megacolon) o úlceras ocasionadas por administración de corticosteroides. Las resecciones intestinales y anastomosis son más frecuentes en perros y gatos debido a cuerpos extraños, neoplasias y trauma. El procedimiento permite la unión de dos secciones del intestino una vez se haya removido la porción afectada. La mayor complicación de este procedimiento es la salida del contenido intestinal hacia la cavidad abdominal provocando peritonitis. El procedimiento reduciría significativamente las complicaciones.

Se intervinieron tres caninos de los cuales un Poodle presentaba cuerpo extraño (semilla de ciruela), un American Sttafordshire Terrier con linfoma digestivo y otro Poodle con perforación intestinal debido a un absceso. Todos los pacientes llegaron a consulta con vómitos, inapetencia, dolor abdominal a la palpación y alteraciones en el hemograma, el principal hallazgo encontrado fue una leucocitosis con neutrofilia. En los tres pacientes se realizó ultrasonido. Durante el procedimiento se pudo detectar afectación en la circulación de una porción del intestino.

Durante la cirugía se eliminó la parte afectada y se colocó un catéter uretral de látex rojo entre las dos porciones del intestino. Esto permitió equiparar el diámetro de ambas partes mediante dilatación, lo que posibilita una unión más efectiva de ambos bordes, además de impedir la salida del contenido intestinal y la no utilización de clamps intestinales durante el procedimiento. Para conseguir una correcta aposición de los bordes se colocaron 4 puntos de fijación. Se continuó una anastomosis continua de una sola capa. Una pequeña incisión permitió retirar el catéter posteriormente y detectar alguna filtración mediante introducción de solución salina. Todos los animales se recuperaron satisfactoriamente y sin complicaciones posteriores a la cirugía.

凶 Autor para correspondencia Ricardo Corrales Viera: racviera@yahoo.com 